Pivodic, L., Pardon, K., Miccinesi, G., Vega Alonso, T., Moreels, S., Donker, G., Arrieta, E., Onwuteaka-Philipsen, B., Deliens, L., Block, L. van den. Hospitalisations at the end of life in four European countries: a population-based study via epidemiological surveillance networks $<7$ Journal of Epidemiology \& Community Health: 2016, 70(5), 430-436 nivel

\begin{tabular}{|l|l|}
\hline $\begin{array}{l}\text { Postprint } \\
\text { Version }\end{array}$ & 1.0 \\
\hline Journal website & http://jech.bmi.com/content/early/2015/11/19/jech-2015-206073.long \\
\hline Pubmed link & $\underline{\text { http://www.ncbi.nlm.nih.gov/pubmed/26584859 }}$ \\
\hline DOI & $10.1136 /$ jech-2015-206073
\end{tabular}

This is a NIVEL certified Post Print, more info at http://www.nivel.eu

\title{
Hospitalisations at the end of life in four European countries: a population-based study via epidemiological surveillance networks
}

\author{
Lara Pivodic1, Koen Pardon1, Guido Miccinesi2, Tomas Vega Alonso3, Sarah \\ MOREEls4, GÉ A DONKER5, ENRIQUE ARRIETA6, BREGJE D ONWUTEAKA-PHILIPSEN7,LUC \\ DELIENS1,8, LIEVE VAN DEN BLOCK1 \\ ${ }^{1}$ Department of Family Medicine \& Chronic Care, End-of-Life Care Research Group, Vrije \\ Universiteit Brussel (VUB) and Ghent University, Brussels, Belgium \\ ${ }^{2}$ ISPO Cancer Prevention and Research Institute, Florence, Italy \\ ${ }^{3}$ Public Health Directorate, Ministry of Health, Autonomous Community of Castile and Leon, \\ Valladolid, Spain \\ ${ }^{4}$ Scientific Institute of Public Health, Brussels, Belgium \\ ${ }^{5}$ NIVEL, Netherlands Institute for Health Services Research, Utrecht, The Netherlands \\ ${ }^{6}$ Health Centre Segovia Rural, Segovia, Spain \\ ${ }^{7}$ Department of Public and Occupational Health, EMGO+ Institute for Health and Care \\ Research, VU University Medical Center, Amsterdam, The Netherlands \\ ${ }^{8}$ Department of Medical Oncology, Ghent University Hospital, Ghent, Belgium
}

\begin{abstract}
Background There is a paucity of cross-national population-based research on hospitalisations of people at the end of life. We aimed to compare, in four European countries, the frequency, time, length of and factors associated with hospitalisations in the last 3 months of life.

Methods Population-based mortality follow-back study via Sentinel Networks of general practitioners (GPs) in Belgium, the Netherlands, Italy and Spain. Using a standardised form, GPs recorded the care in the last 3 months of life of every deceased practice patient ( $\geq 18$ years; 1 January 2009 to 31 December 2011). Sudden deaths were excluded.

Results We studied 4791 deaths that GPs described as non-sudden (66\% of all registered deaths). Between 49\% (the Netherlands) and 56\% (Belgium) of patients were hospitalised at least once in the last 3 months of life. Readmissions were less frequent in the Netherlands (8\%) than in the other countries $(15-20 \%$, $\mathrm{p}<0.001)$. Chances of being hospitalised increased over the last 10 days of life across countries but remained lowest in the Netherlands (Belgium: $21-37 \%$, the Netherlands: $15-29 \%$, Italy: $16-37 \%$, Spain: 14-31\%). Hospitalisations in the last week of life were more likely if patients resided at home rather than in a care home (ORs and 95\% CIs Belgium: 1.94 (1.28 to 2.94); the Netherlands:
\end{abstract}


Pivodic, L., Pardon, K., Miccinesi, G., Vega Alonso, T., Moreels, S., Donker, G., Arrieta, E., Onwuteaka-Philipsen, B., Deliens, L., Block, L. van den. Hospitalisations at the end of life in four European countries: a population-based study via epidemiological surveillance networks $<7$ Journal of Epidemiology \& Community Health: 2016, 70(5), 430-436

2.61 (1.10 to 6.18); Spain: 4.72 (1.64 to 13.57); non-significant in Italy) and less likely if the GP knew the patient's preferred place of death (ORs and 95\% CIs Belgium: 0.52 (0.36 to 0.74 ); the Netherlands: 0.48 (0.25 to 0.91); Spain: 0.24 (0.13 to 0.44$)$, non-significant in Italy).

Conclusions The use of hospitals at the end-of-life increased over the last weeks of life of patients in all countries studied, but remained lowest in the Netherlands, as did the rate of readmissions. This may be due to gatekeeping by GPs who are trained and supported in preventing hospital readmissions at the end of life.

\section{INTRODUCTION}

A considerable number of people who are hospitalised are nearing death.1,2 At the same time, research shows that hospitalisations at the end of life may run contrary to the wishes of patients and their families, 3,4 and carry the risk of patients receiving overly aggressive, fragmented, poorly coordinated care with insufficient information exchange between healthcare providers, and poor planning and completion of followup care.5-10

Furthermore, hospital admissions of people nearing the end-of-life contribute significantly to total healthcare expenditure,11-13 and it is unlikely that hospitals will be able to bear the burden of end-of-life care for the growing number of patients who are projected to die from chronic diseases in the future.14-16 As a result, many countries aim to reduce hospital use by people at the end of life and strengthen endof-life care in community settings. 17

To be effective, national public health policies and strategies on hospitalisations at the end-of-life require a sound epidemiological evidence base on the extent, time patterns and determinants of hospital use at the end of life. Previous research has investigated the percentage of patients who die in hospital, using death certificate data.18-20 However, death certificates can only indicate whether a patient was hospitalised when they died, and they hold no information on the frequency, time and length of hospitalisations over the weeks prior to death, whether death was sudden and unexpected, and on whether patients had expressed a preference to die in a particular location.

In an effort to overcome these limitations, we conducted a population-based study of hospitalisations over the last 3 months of life through Sentinel Networks of general practitioners (GPs) in four European countries, Belgium, the Netherlands, Italy and Spain. Cross-national comparisons of hospitalisations and associated factors can help to identify patterns that are common across countries or country specific and they can guide the search for contextual factors that may influence hospital use at the end of life.

All four countries studied have universal health coverage with primary care systems that are relatively strong in Belgium, the Netherlands and Spain, and of medium strength in Italy.21 The countries are similar in terms of features of primary care that may have an impact on hospital admissions at the end of life, such as access and continuity of primary care, but they differ with regard to coordination of primary care, which was relatively high in the Netherlands, relatively low in Belgium, and medium in Spain and Italy.21 Hospitalisations at the end of life could also be influenced by the availability of specialist palliative care services. These are 
Pivodic, L., Pardon, K., Miccinesi, G., Vega Alonso, T., Moreels, S., Donker, G., Arrieta, E., Onwuteaka-Philipsen, B., Deliens, L., Block, L. van den. Hospitalisations at the end of life in four European countries: a population-based study via epidemiological surveillance networks $<7$ Journal of Epidemiology \& Community Health: 2016, 70(5), 430-436

established in all four countries, but the countries differ with regard to the care settings in which these services predominantly operate (eg, hospitals, community settings, nursing homes) and their geographical distribution (evenly distributed in Belgium and the Netherlands; large geographic variation in Italy and Spain).22 To the best of our knowledge, this is the first cross-national, population-based study that provides detailed original data on hospitalisations at the end of life in four countries. We aimed to describe and compare, in four European countries, the frequency and time of hospitalisations in the last 3 months of life of people who died non-suddenly; the length of and location prior to the final hospitalisation for patients who died in hospital; and the factors associated with a hospitalisation in the last 7 days of life.

\section{METHODS}

\section{Study design}

We conducted a cross-national mortality follow-back study in Belgium, the Netherlands, Italy and Spain. The data were collected through nationwide Sentinel Networks of GPs.23 These are regional or nationwide epidemiological surveillance networks consisting of representative samples of GPs. From 1 January 2009 to 31 December 2010, in Belgium, the Netherlands and Italy, and from 1 January 2010 to 31 December 2011, in Spain, GPs registered, weekly, all deaths of patients in their practice and recorded their sociodemographic characteristics, four successive causes of death (ie, from the primary/underlying cause of death to the immediate cause of death), the care the patients received in the last 3 months of life, and whether their death was sudden and totally unexpected. We focused on the last 3 months of life as this is a commonly accepted period for studying end-of-life care.24-26 A number of quality control measures were applied to ensure valid and reliable cross-national data23; previous studies have demonstrated the potential of this design in collecting population-based epidemiological data on end-of-life care.27-30

\section{Setting and population}

The Sentinel Networks in Belgium and the Netherlands were nationwide with a population coverage of $1.8 \%$ and $0.8 \%$ in 2009 , and $1.5 \%$ and $0.8 \%$ in 2010 , respectively. The Italian network covered $4.3 \%$ (2009) and $2.7 \%$ (2010) of the population of the nine participating health districts (spread across the country). The Spanish networks operated in two autonomous communities. In the Valencian Community, their population coverage of those aged 18 years or over was $2.2 \%$ in 2010 and 2.1\% in 2011; in Castile and Leon, the respective figures were 3.8\% in 2010 and $3.4 \%$ in 2011. The participating GPs had an adequate geographical distribution and were representative of the general population of GPs in the respective country (or region in Spain) with regard to gender and age. 23

The GPs registered the death of each patient in their practice who was aged 18 years or over. We excluded deaths that GPs judged as sudden in order to obtain a sample of people for whom end-of-life care had been a realistic option.31 Furthermore, we excluded deaths in nursing homes in the Netherlands as these residents are treated by specialised elderly care physicians and therefore not within the GPs' scope. Residents of homes for elderly people in the Netherlands are treated by GPs and were therefore included in the study. A detailed analysis of the representativeness of the sample obtained through this study can be found in the published study 
Pivodic, L., Pardon, K., Miccinesi, G., Vega Alonso, T., Moreels, S., Donker, G., Arrieta, E., Onwuteaka-Philipsen, B., Deliens, L., Block, L. van den. Hospitalisations at the end of life in four European countries: a population-based study via epidemiological surveillance networks $<7$ Journal of Epidemiology \& Community Health: 2016, 70(5), 430-436

protocol.23 The protocol shows that the deaths registered by the GP networks were representative for all deaths in the participating countries in terms of age, gender and place of death, with the exception of nursing home deaths in the Netherlands and the fact that GPs under-reported a small number of sudden hospital deaths in all countries as well as non-sudden hospital deaths and deaths of people under 65 years in Belgium.

\section{Outcomes and covariates}

The main outcomes were (1) how many patients were hospitalised in the last 3 months of life and how many times, (2) how many patients were hospitalised in the last 7 days of life, (3) how many patients were admitted to hospital at each of the last 90 days of life, (4) the time of the final hospitalisation (ie, in the course of which the patient died) in days before death, and (5) the care setting prior to the final hospitalisation. A person was considered as readmitted to hospital in the last 3 months of life if they had more than one hospital admission in this period. Covariates included the patient's age, gender, the primary cause of death, whether the GP or another physician had determined the diagnosis of dementia, the longest place of residence in the last year of life ('at home/with family' vs 'nursing home/care home'), number of contacts with the GP over the last 3 months of life, the GP's knowledge of the patient's preferred place of death and provision of specialist (multidisciplinary) palliative care.

\section{Measures}

The GPs of the Sentinel Networks weekly registered each deceased patient of their practice by filling in a standardised registration form. This form consisted of structured closed-ended items and is available in Dutch, French, Italian, Spanish and English.

Information on hospitalisations and other locations of care was collected by asking GPs to indicate on the registration form the patient's place of death, the three preceding locations of care (in chronological order) in the last 3 months of life, and the length of stay (in days) in each of these locations. From this information we were able to determine for each patient the place of care at each of the last 90 days of life. The location 'hospital' excluded palliative care units in hospitals, these were recorded as a separate location. When filling in the registration forms, the GPs were asked to include any information available from patient records and hospital physicians.

\section{Statistical analyses}

We grouped age as 18 to 64,65 to 84 and $\geq 85$ years, corresponding to commonly applied definitions of the old and oldest old. 32 We compared the characteristics of the samples in the four countries using Pearson's $\chi^{2}$ tests. We calculated the percentage of people hospitalised at least once in the last 3 months of life and the percentage of people who were transferred to hospital in the last 7 days of life (denominator: all non-sudden deaths) as well as the percentage of people hospitalised once, twice or three times or more (denominator: persons hospitalised at least once). We tested whether there were significant differences between countries in these outcomes, using multivariable logistic regression analyses adjusted for country differences in age, gender, cause of death, longest place of residence in the last year of life, involvement of a multidisciplinary palliative care team and presence of dementia. 
Pivodic, L., Pardon, K., Miccinesi, G., Vega Alonso, T., Moreels, S., Donker, G., Arrieta, E., Onwuteaka-Philipsen, B., Deliens, L., Block, L. van den. Hospitalisations at the end of life in four European countries: a population-based study via epidemiological surveillance networks $<7$ Journal of Epidemiology \& Community Health: 2016, 70(5), 430-436

To describe the time at which people were hospitalised over the last 3 months of life, we plotted the percentage of patients in hospital against the number of days before death $(0-90)$ in a line chart for each country separately.

For the group of patients who died in hospital, we described the length of the final hospital admission before death and the percentage of people for whom home, nursing home/care home or hospice/palliative care unit was the location prior to the final hospitalisation. We tested whether the percentages differed significantly between countries using multivariable logistic regression analyses adjusted for country differences in age, gender, cause of death and presence of dementia. To determine which factors were associated with a hospitalisation in the last 7 days of life, we conducted, separately for each country, a multivariable logistic regression analysis with the dependent variable being: hospitalised in the last 7 days of life versus not hospitalised. Independent variables were simultaneously entered and chosen based on factors that previous literature found to be associated with place of care or place of death.33 All regression models were checked for multicollinearity (variance inflation factors). All statistical tests were performed with a significance level of $\alpha<0.05$. Analyses were performed in IBM SPSS Statistics V.22 and Microsoft Excel 2010.

\section{Ethics}

The study protocol was approved by the Ethical Review Board of Brussels University Hospital of the Vrije Universiteit Brussel, Belgium, and by the Local Ethical Committee 'Comitato Etico della Azienda USL n 9 di Grosseto' in Tuscany, Italy. As the data collection was retrospective and anonymous, no ethical approval was required in the Netherlands and Spain.

\section{RESULTS}

The GPs in the four countries registered 7411 deaths of which 4877 (65.8\%) were non-sudden. Following the exclusion of patients who died in a nursing home in the Netherlands (52, 7.6\% of non-sudden deaths) or whose place of death was not known or 'elsewhere' (34, $0.7 \%$ of non-sudden deaths), we studied 4791 deaths, that is, 1596 in Belgium, 633 in the Netherlands, 1827 in Italy and 735 in Spain. There were 208 cases (4\% of all non-sudden deaths) with incomplete trajectories of locations of care, which meant that we could not calculate the primary outcomes for them (ie, hospitalisations and locations prior to hospitalisations). They were therefore excluded from the respective analyses.

Between $32 \%$ (the Netherlands) and $45 \%$ (Spain) of patients were aged 85 years or over when they died, and between $46 \%$ (Spain) and 54\% (Belgium) were female (table 1). Cancer was the cause of death in $37 \%$ (Belgium) to $53 \%$ (the Netherlands) of cases. Between 28\% (the Netherlands) and 39\% (Italy) died in hospital, and between 23\% (Belgium) and 46\% (Italy, Spain) died at home. In all countries, home was the longest place of residence in the last year of life for the majority of patients. Around one-third of patients had dementia in Belgium, Italy and Spain; in the Netherlands, where nursing home deaths were excluded, 13\% had dementia. 
Pivodic, L., Pardon, K., Miccinesi, G., Vega Alonso, T., Moreels, S., Donker, G., Arrieta, E., Onwuteaka-Philipsen, B., Deliens, L., Block, L. van den. Hospitalisations at the end of life in four European countries: a population-based study via epidemiological surveillance networks $<7$ Journal of Epidemiology \& Community Health: 2016, 70(5), 430-436

\section{[TABLE 1]}

\section{Hospital use in the last 3 months of life}

Forty-nine per cent of patients who died non-suddenly in the Netherlands, $52 \%$ in Spain, 54\% in Italy and 56\% in Belgium, were hospitalised at least once in the last 3 months of life (table 2). Of these, between $80 \%$ (Spain) and $92 \%$ (the Netherlands) were admitted once, and between $8 \%$ (the Netherlands) and 20\% (Spain) were admitted twice. In all countries studied, $0.3 \%$ or fewer were admitted three or more times. Twelve per cent in the Netherlands, $14 \%$ in Belgium, $15 \%$ in Italy and $18 \%$ in Spain were hospitalised in the last 7 days of life.

\section{[TABLE 2]}

\section{Time pattern for hospitalisations in the last 3 months of life}

Figure 1 shows the percentage of patients in hospital at each of the last 90 days of life. This percentage (between $5 \%$ and $7 \%$ at 90 days before death) increased towards the day of death in all four countries. Over the last 10 days of life, the percentage increased from $24 \%$ to $36 \%$ in Belgium, from $19 \%$ to $28 \%$ in the Netherlands, from $21 \%$ to $39 \%$ in Italy and from $19 \%$ to $37 \%$ in Spain.

\section{[FIGURE 1]}

\section{Hospital use by those who died in hospital}

Between 45\% (Spain) and 56\% (Italy) of patients who died in hospital were transferred there between the second and fourth week before death (table 3 ). Between $17 \%$ in Italy and $24 \%$ in Spain were admitted $1-3$ days before death. The most common location prior to a hospitalisation during which the patient died was home (for 77\% (Belgium), 81\% (Spain), 84\% (the Netherlands) and 92\% (Italy) of patients).

\section{[TABLE 3]}

\section{Factors associated with hospital admission in the last $\mathbf{7}$ days of life}

The multivariable analysis showed that, in all countries except Italy, the probability of a late hospitalisation was lower if the GP was informed of the patient's preferred place of death and if nursing/care home (rather than home) was the longest place of residence in the patient's last year of life (table 4). Additionally, the involvement of a multidisciplinary palliative care team in Belgium and the Netherlands, and female gender and six or more contacts with the GP in the last 3 months of life in Belgium, were associated with a lower probability of a late hospitalisation.

\section{[TABLE 4]}

\section{DISCUSSION}

In all countries studied, a similar percentage of people were hospitalised once in the last 3 months of life (around half of all non-sudden deaths) but the percentage of those hospitalised twice or more times was significantly lower in the Netherlands than in the other countries. There was a considerable increase in the probability of being hospitalised over the last 90 days, and particularly the last 10 days of life, in all 
Pivodic, L., Pardon, K., Miccinesi, G., Vega Alonso, T., Moreels, S., Donker, G., Arrieta, E., Onwuteaka-Philipsen, B., Deliens, L., Block, L. van den. Hospitalisations at the end of life in four European countries: a population-based study via epidemiological surveillance networks $<7$ Journal of Epidemiology \& Community Health: 2016, 70(5), 430-436

countries studied, but overall it remained lowest in the Netherlands. The factors most consistently associated with a lower probability of being hospitalised in the last 7 days of life were the GP's knowledge of the patient's preferred place of death and residing in a care home rather than at home.

Research has shown that a large number of people with life-threatening illnesses prefer to and could be cared for in community-settings towards the end of life.4,28 Yet the results of our study show that all countries we studied face the challenge that large numbers of people are admitted to hospital towards the end of life. A hospitalisation may be unavoidable for a number of reasons, such as sudden exacerbation of symptoms, or low availability of formal home care.34,35 However, based on the findings of our study and those of previous research, we hypothesise that the way chronic and end-of-life care are organised may stimulate hospitalisations at the end of life.

The percentage of people hospitalised at each of the last 90 days of life was generally lower in the Netherlands than in the other countries. It also remained notably low over the last 10 days of life, while there was a strong increase in the other countries. Despite a similar percentage of people who were hospitalised at least once in all four countries, the percentage of people readmitted to hospital in the Netherlands was only half as high as that in the other countries. It has been suggested that GPs' role as gatekeepers to secondary and tertiary care in the Netherlands, may reduce hospitalisations and hospital deaths.36 However, our cross-national comparison shows that this alone is not a sufficient explanation. In Spain and Italy, where GPs also are gatekeepers, hospitalisation rates are considerably higher than in the Netherlands. It is thus perhaps gatekeeping by GPs who are trained and supported in preventing inappropriate hospitalisations at the end of life, combined with a high level of coordination in primary care, 21 that helps reduce hospitalisations and hospital deaths rather than the gatekeeping system alone. This hypothesis is supported by evidence from qualitative research that suggests that GPs' competence and attitude regarding end-of-life care and support by local specialist palliative care services are important in avoiding hospitalisations at the end of life.36 It might thus be a combination of structural factors of the healthcare system (eg, gatekeeping role, coordination of primary care) and care provision factors (eg, specialist support) that either drives or curbs these hospitalisations.

Hospitalisations in the last weeks of life may also be influenced by the availability of palliative and long-term care resources. In Belgium and Spain, for instance, many palliative care services are based in hospitals,37 and another study has shown that GPs in these two countries cited palliative care as the reason for more than one in three terminal hospitalisations (hospital admissions during which the patient died).38 Our data showed that the involvement of multidisciplinary palliative care teams was associated with fewer late hospitalisations in Belgium and the Netherlands, but this was not so in Italy and Spain. This suggests that specialist palliative care support alone may not be sufficient in preventing late hospitalisations but that it needs additional structures and resources to draw on, such as long-term care facilities and formal home care, which are less available in Italy and Spain. For instance, Italy has the lowest number of long-term care beds per 1000 population aged 65 years and over among Organisation for Economic Cooperation and Development (OECD) countries,39 which means that many people are hospitalised when the care provided at home, usually by family carers, is insufficient. 40 
Pivodic, L., Pardon, K., Miccinesi, G., Vega Alonso, T., Moreels, S., Donker, G., Arrieta, E., Onwuteaka-Philipsen, B., Deliens, L., Block, L. van den. Hospitalisations at the end of life in four European countries: a population-based study via epidemiological surveillance networks $<7$ Journal of Epidemiology \& Community Health: 2016, 70(5), 430-436

In all countries except Italy, hospitalisations in the last week of life were nivel significantly less likely to occur if the GP knew the patient's preferred place of death. People generally prefer to die at home, 3 hence this result could mean that communication about care preferences may reduce the likelihood of unwanted hospital admissions at the end of life. In all countries except Italy, patients who resided at home were more likely than residents of care homes or nursing homes to be hospitalised in the last week of life. This result highlights the importance for researchers and policy-makers to gain a better understanding of the types, and extent of care and support that should be provided to terminally ill people at home and to their family carers, in order to reduce the risk of late hospital admissions.

This study has several strengths. We maximised comparability by applying the same method across all four countries. We were able to study not only whether a patient died in hospital but also the frequency, time and length of hospitalisations and the previous locations of residence in the last 3 months of life. By selecting non-sudden deaths, we were able to identify a population for whom palliative and end-of-life care was a relevant consideration. However, this study also has limitations. It relies on GPs' retrospective accounts of patients' hospital admissions and other care-related information. Recall bias cannot be ruled out, but it was likely limited as the GPs conducted the registrations on a weekly basis. Furthermore, due to the exclusion of nursing home deaths from the Netherlands, we did not have information from this country, on a sample of usually very old patients with complex health problems.

\section{CONCLUSION}

This study found that hospitals were frequently used as locations of care for people nearing the end of life in all four countries studied, and that fewer patients were readmitted to hospital in the Netherlands. Across all countries, the likelihood of being hospitalised increased considerably towards the end of life, but it remained lowest in the Netherlands. Some of these hospitalisations may be unavoidable but our cross-national comparison suggests that care can be organised in a way that reduces the risk of hospitalisations at the end of life and enables people to receive care in their usual living environment in the last phase of life.

\section{What is already known on this subject}

Hospitalisations of people who are approaching the end-of-life carry risks to coordination, continuity and, potentially, safety of care, and may run contrary to the wishes of patients and their families.

Yet a considerable number of people who are hospitalised are nearing death. There is need for population-based and cross-national epidemiological data on hospitalisations at the end of life in order to create an evidence base for the development of public health policies and strategies on hospital use at the end of life.

\section{What this study adds}

The chances of being hospitalised increased over the last 3 months of life, and particularly over the last 10 days of life, in all countries studied, but they remained lowest in the Netherlands.

The percentage of people hospitalised once was similar across countries, but the percentage of people readmitted to hospital was lowest in the Netherlands. The cross-national comparison suggests that end-of-life care can be organised in a way that reduces the risk of hospitalisations at the end of life; for instance, through 
Pivodic, L., Pardon, K., Miccinesi, G., Vega Alonso, T., Moreels, S., Donker, G., Arrieta, E., Onwuteaka-Philipsen, B., Deliens, L., Block, L. van den. Hospitalisations at the end of life in four European countries: a population-based study via epidemiological surveillance networks $<7$ Journal of Epidemiology \& Community Health: 2016, 70(5), 430-436

gatekeeping by general practitioners who are trained and supported in preventing inappropriate hospital readmissions at the end of life.

\section{ACKNOWLEDGMENTS}

The authors would like to thank the general practitioners of the Sentinel Networks of the four participating countries for collecting the data for this study.

\section{FOOTNOTES}

Twitter Follow Lara Pivodic at @LaraPivodic

Contributors LVdB and LD conceived and designed the EURO-SENTIMELC study, and $\mathrm{LP}, \mathrm{KP}, \mathrm{LVdB}$ and $\mathrm{LD}$ conceived the analysis presented in this article. GM, TVA, SM, BO-P, GAD and EA collected the data. LP analysed the data. LVdB, KP and LD made substantial contributions to the data analysis. All the authors made substantial contributions to the interpretation of the data. LP wrote the paper. KP, GM, TVA, SM, GAD, EA, BO-P, LD and LVdB critically revised the manuscript for important intellectual content. All the authors approved of the final version to be submitted for publication. All the authors agree to be accountable for all aspects of the work in ensuring that questions related to the accuracy or integrity of any part of the work are appropriately investigated and resolved.

Funding LVdB was supported through a postdoctoral grant from The Research Foundation Flanders (FWO), Belgium, and LP was supported by the Willy Gepts Scientific Fund (Wetenschappelijk Fonds Willy Gepts) of Brussels University Medical Center.

Competing interests None declared.

Ethics approval The study protocol was approved by the Ethical Review Board of Brussels University Hospital of the Vrije Universiteit Brussel, Belgium, and by the Local Ethical Committee 'Comitato Etico della Azienda USL n 9 di Grosseto' in Tuscany, Italy.

Provenance and peer review Not commissioned; externally peer reviewed.

\section{REFERENCES}

1 Clark D, Armstrong M, Allan A, et al. Imminence of death among hospital inpatients: prevalent cohort study. Palliat Med 2014;28:474-9.

Hua MS, Li G, Blinderman CD, et al. Estimates of the need for palliative care consultation across United States intensive care units using a trigger-based model.

Am J Respir Crit Care Med 2014;189:428-36.

3 Gomes B, Calanzani N, Gysels M, et al. Heterogeneity and changes in preferences for dying at home: a systematic review. BMC Palliat Care 2013;12:7.

4 Wilson DM, Cohen J, Deliens L, et al. The preferred place of last days: results of a representative population-based public survey. J Palliat Med 2013;16:502-8.

5 Boockvar K, Fishman E, Kyriacou CK, et al. Adverse events due to discontinuations in drug use and dose changes in patients transferred between acute and long-term care facilities. Arch Intern Med 2014;164:545-50.

6 Coleman EA. Falling through the cracks: challenges and opportunities for improving transitional care for persons with continuous complex care needs. J Am Geriatr Soc 2003;51:549-55.

7 Wunsch H, Linde-Zwirble WT, Harrison DA, et al. Use of intensive care services during terminal hospitalizations in England and the United States. Am J Respir Crit Care Med 2009;180:875-80. 
Pivodic, L., Pardon, K., Miccinesi, G., Vega Alonso, T., Moreels, S., Donker, G., Arrieta, E., Onwuteaka-Philipsen, B., Deliens, L., Block, L. van den. Hospitalisations at the end of life in four European countries: a population-based study via epidemiological surveillance networks 7 Journal of Epidemiology \& Community Health: 2016, 70(5), 430-436

$8 \mathrm{Hu}$ W, Yasui Y, White J, et al. Aggressiveness of end-of-life care for patients with nivet colorectal cancer in Alberta, Canada: 2006-2009. J Pain Symptom Manage 2014;47:23144.

9 Huynh TN, Kleerup EC, Wiley JF, et al. The frequency and cost of treatment perceived to be futile in critical care. JAMA Intern Med 2013;173:1887-94.

10 Walling AM, Asch SM, Lorenz KA, et al. The quality of care provided to hospitalized patients at the end of life. Arch Intern Med 2010;170:1057-63.

11 Hatziandreu E, Archontakis F, Daly A. The potential cost savings of greater use of homeand hospice-based end of life care in England. 2008. http://www.rand.org/ pubs/technical_reports/TR642.html (accessed 6 Sep 2014).

12 Fassbender $\overline{\mathrm{K}}$, Fainsinger RL, Carson M, et al. Cost trajectories at the end of life: the Canadian experience. J Pain Symptom Manage 2009;38:75-80.

13 Gardiner C, Ward S, Gott M, et al. Economic impact of hospitalisations among patients in the last year of life: an observational study. Palliat Med 2014;28:422-9.

14 Gomes B, Higginson IJ. Where people die (1974-2030): past trends, future projections and implications for care. Palliat Med 2008;22:33-41.

15 Kellehear A, Sallnow L. Public health and palliative care: an historical overview. In: Sallnow L, Kumar S, Kellehear A, eds. International perspectives on public health and palliative care. Abingdon, UK: Routledge Studies in Public Health, 2012:1-12.

16 Mathers CD, Loncar D. Projections of global mortality and burden of disease from 2002 to 2030. PLoS Med 2006;3:e442.

17 Van Beek K, Woitha K, Ahmed N, et al. Comparison of legislation, regulations and national health strategies for palliative care in seven European countries (results from the Europall research group): a descriptive study. BMC Health Serv Res 2013;13:275.

18 Cohen J, Houttekier D, Onwuteaka-Philipsen B, et al. Which patients with cancer die at home? A study of six European countries using death certificate data. J Clin Oncol 2010;28:2267-73.

19 Gao W, Ho YK, Verne J, et al. Changing patterns in place of cancer death in England: a population-based study. PLoS Med 2013;10:e1001410.

20 Houttekier D, Cohen J, Pepersack T, et al. Dying in hospital: a study of incidence and factors related to hospital death using death certificate data. Eur J Public Health 2014;24:751-6.

21 Kringos DS, Boerma WGW, Hutchinson A, et al. Building primary care in a changing Europe. Copenhagen: WHO Regional Office for Europe, 2015.

22 Centeno C, Lynch T, Donea O, et al. EAPC atlas of palliative care in Europe 2013: full edition. Milan: EAPC Press, 2013.

23 Van den Block L, Onwuteaka-Philipsen B, Meeussen K, et al. Nationwide continuous monitoring of end-of-life care via representative networks of general practitioners in Europe. BMC Fam Pract 2013;14:73.

24 Costantini M, Beccaro M, Merlo F. The last three months of life of Italian cancer patients. Methods, sample characteristics and response rate of the Italian Survey of the Dying of Cancer (ISDOC). Palliat Med 2005;19:628-38.

25 Gao W, Gulliford M, Bennett MI, et al. Managing cancer pain at the end of life with multiple strong opioids: a population-based retrospective cohort study in primary care. PLoS ONE 2014;9:e79266.

26 Gomes B, McCrone P, Hall S, et al. Variations in the quality and costs of end-of-life care, preferences and palliative outcomes for cancer patients by place of death: the QUALYCARE study. BMC Cancer 2010;10:400.

$27 \mathrm{Ko} \mathrm{W}$, Beccaro M, Miccinesi G, et al. Awareness of general practitioners concerning cancer patients' preferences for place of death: evidence from four European countries. Eur J Cancer 2013;49:1967-74.

28 Pivodic L, Pardon K, Van den Block L, et al. Palliative care service use in four European countries: a cross-national retrospective study via representative networks of general practitioners. PLoS ONE 2013;8:e84440.

29 Pivodic L, Van den Block L, Pardon K, et al. Burden on family carers and care-related financial strain at the end of life: a cross-national population-based study. Eur J Public Health 2014;24:819-26. 
Pivodic, L., Pardon, K., Miccinesi, G., Vega Alonso, T., Moreels, S., Donker, G., Arrieta, E., Onwuteaka-Philipsen, B., Deliens, L., Block, L. van den. Hospitalisations at the end of life in four European countries: a population-based study via epidemiological surveillance networks $<$ Journal of Epidemiology \& Community Health: 2016, 70(5), 430-436

30 Evans N, Costantini M, Pasman HR, et al. End-of-life communication: a retrospective survey of representative general practitioner networks in four countries. J Pain Symptom Manage 2014;47:604-19.

31 Borgsteede SD, Deliens L, Francke AL, et al. Defining the patient population: one of the problems for palliative care research. Palliat Med 2006;20:63-8.

32 National Institute on Aging. National Institutes of Health. U.S. Department of Health and Human Services. Why population aging matters. A global perspective. 2007.

https://www.nia.nih.gov/research/publication/why-population-aging-matters-global perspective (accessed 6 Sep 2015).

33 Gomes B, Higginson IJ. Factors influencing death at home in terminally ill patients with cancer: systematic review. BMJ 2006;332:515-21.

34 Reyniers T, Houttekier D, Cohen J, et al. What justifies a hospital admission at the end of life? A focus group study on perspectives of family physicians and nurses.

Palliat Med 2014;28:941-8.

35 Gott M, Gardiner C, Ingleton C, et al. What is the extent of potentially avoidable admissions amongst hospital inpatients with palliative care needs? BMC Palliat Care 2013;12:9.

36 Reyniers T, Houttekier D, Pasman HR, et al. The family physician's perceived role in preventing and guiding hospital admissions at the end of life: a focus group study.

Ann Fam Med 2014;12:441-6.

37 Centeno C, Pons JJ, Lynch T, et al. EAPC atlas of palliative care in EuropeCartographic edition. Milan: EAPC Press, 2013.

38 Van den Block L, Pivodic L, Pardon K, et al. Transitions between health care settings in the final three months of life in four EU countries. Eur J Public Health 2015;25:569-75.

39 OECD. Long-term care beds in institutions and hospitals. Health at a Glance 2013, OECD Indicators. 2013. http://www.oecd-ilibrary.org/social-issues-migration-health/ health-at-aglance-2013/long-term-care-beds-in-institutions-and-hospitals_health_glance-2013-78-en (accessed 6 Sep 2015).

40 Beccaro M, Costantini M, Giorgi Rossi P, et al. Actual and preferred place of death of cancer patients. Results from the Italian survey of the dying of cancer (ISDOC).

J Epidemiol Community Health 2006;60:412-16. 
Pivodic, L., Pardon, K., Miccinesi, G., Vega Alonso, T., Moreels, S., Donker, G., Arrieta, E., Onwuteaka-Philipsen, B., Deliens, L., Block, L. van den. Hospitalisations at the end of life in four European countries: a population-based study via epidemiological surveillance networks $<7$ Journal of Epidemiology \& Community Health: 2016, 70(5), 430-436

\section{TABLES AND FIGURES}

\begin{tabular}{|c|c|c|c|c|c|c|c|c|c|}
\hline \multirow[b]{2}{*}{ Patient characteristics* } & \multicolumn{2}{|c|}{$B E(N=1596)$} & \multicolumn{2}{|c|}{ NL $(\mathrm{N}=633)$} & \multicolumn{2}{|c|}{ IT $(\mathrm{N}=1827)$} & \multicolumn{2}{|c|}{ ES $(N=735)$} & \multirow[b]{2}{*}{$\mathrm{p}$ Valuet } \\
\hline & $\mathrm{n}$ & Per cent & $\mathrm{n}$ & Per cent & $\mathrm{n}$ & Per cent & $\mathrm{n}$ & Per cent & \\
\hline \multicolumn{10}{|l|}{ Age (years) } \\
\hline $18-64$ & 217 & 14 & 117 & 19 & 229 & 13 & 74 & 10 & \multirow[t]{3}{*}{$<0.001$} \\
\hline $65-84$ & 750 & 47 & 316 & 50 & 857 & 47 & 331 & 45 & \\
\hline$\geq 85$ & 617 & 39 & 200 & 32 & 741 & 41 & 330 & 45 & \\
\hline \multicolumn{10}{|l|}{ Gender } \\
\hline Female & 864 & 54 & 331 & 53 & 973 & 53 & 333 & 46 & \multirow[t]{2}{*}{0.001} \\
\hline Male & 727 & 46 & 295 & 47 & 854 & 47 & 395 & 54 & \\
\hline \multicolumn{10}{|l|}{ Cause of death } \\
\hline Cancer & 590 & 37 & 334 & 53 & 824 & 46 & 272 & 38 & \multirow[t]{6}{*}{$<0.001$} \\
\hline Cardiovascular diseases & 236 & 15 & 93 & 15 & 374 & 21 & 145 & 20 & \\
\hline Respiratory diseases & 170 & 11 & 49 & 8 & 130 & 7 & 83 & 12 & \\
\hline Diseases of the nervous system & 113 & 7 & 19 & 3 & 105 & 6 & 36 & 5 & \\
\hline Stroke & 109 & 7 & 24 & 4 & 180 & 10 & 62 & 9 & \\
\hline Other & 376 & 24 & 112 & 18 & 170 & 10 & 122 & 17 & \\
\hline \multicolumn{10}{|l|}{ Place of death } \\
\hline Home & 367 & 23 & 276 & 44 & 846 & 46 & 338 & 46 & \multirow[t]{4}{*}{$<0.001$} \\
\hline Hospital & 580 & 36 & 177 & 28 & 716 & 39 & 274 & 37 & \\
\hline Nursing home/care home & 499 & 31 & 114 & 18 & 164 & 9 & 86 & 12 & \\
\hline Hospice/PCU & 150 & 9 & 66 & 10 & 101 & 6 & 37 & 5 & \\
\hline \multicolumn{10}{|c|}{ Longest place of residence in the last year of life } \\
\hline At home/with family & 1041 & 67 & 490 & 79 & 1691 & 94 & 637 & 89 & \multirow[t]{2}{*}{$<0.001$} \\
\hline Nursing home/care home & 507 & 33 & 134 & 22 & 111 & 6 & 78 & 11 & \\
\hline \multicolumn{10}{|l|}{ Presence of dementia } \\
\hline Yes (mild or severe) & 492 & 31 & 79 & 13 & 521 & 29 & 215 & 30 & \multirow[t]{2}{*}{$<0.001$} \\
\hline No & 1078 & 69 & 532 & 87 & 1280 & 71 & 495 & 70 & \\
\hline
\end{tabular}

Table 2 Hospital admissions in the last 3 months of life of people who died non-suddenly

\begin{tabular}{|c|c|c|c|c|c|c|c|c|c|}
\hline \multirow[b]{2}{*}{ Hospital use in the last three months of life ${ }^{*}$} & \multicolumn{2}{|c|}{$\begin{array}{l}\mathrm{BE} \\
\mathrm{N}=1596\end{array}$} & \multicolumn{2}{|c|}{$\begin{array}{l}\mathrm{NL} \\
\mathrm{N}=633\end{array}$} & \multicolumn{2}{|c|}{$\begin{array}{l}\text { IT } \\
\mathrm{N}=1827\end{array}$} & \multicolumn{2}{|c|}{$\begin{array}{l}\mathrm{ES} \\
\mathrm{N}=735\end{array}$} & \multirow[b]{2}{*}{$\mathrm{p}$ Value } \\
\hline & $\mathrm{n}$ & Per cent $(95 \% \mathrm{Cl})$ & $\mathrm{n}$ & Per cent $(95 \% \mathrm{Cl})$ & $\mathrm{n}$ & Per cent $(95 \% \mathrm{Cl})$ & $\mathrm{N}$ & Per cent $(95 \% \mathrm{Cl})$ & \\
\hline Hospitalised at least once & 887 & 56 (54 to 58 ) & 301 & $49(45$ to 53$)$ & 947 & 54 (52 to 56$)$ & 337 & 52 (48 to 56$)$ & $<0.001 \dagger$ \\
\hline Hospitalised in last 7 days of life & 209 & 14 (12 to 16$)$ & 74 & 12 (9 to 15$)$ & 255 & 15 (13 to 17$)$ & 114 & 18 (15 to 21$)$ & $0.01+$ \\
\hline \multicolumn{10}{|l|}{ If hospitalised at least once } \\
\hline Hospitalised once & 735 & 83 (81 to 85 ) & 276 & 92 (89 to 95$)$ & 804 & 85 (83 to 87$)$ & 269 & 80 (76 to 84 ) & $0.002 \ddagger$ \\
\hline Hospitalised twice & 150 & 17 (15 to 19$)$ & 25 & 8 (5 to 11$)$ & 141 & 15 (13 to 17$)$ & 67 & 20 (16 to 24$)$ & \\
\hline Hospitalised three times or more & 2 & $0.2(0.0)$ & 0 & $0.0(0.0)$ & 2 & $0.2(0.0)$ & 1 & $0.3(0.0)$ & \\
\hline
\end{tabular}


Pivodic, L., Pardon, K., Miccinesi, G., Vega Alonso, T., Moreels, S., Donker, G., Arrieta, E., Onwuteaka-Philipsen, B., Deliens, L., Block, L. van den. Hospitalisations at the end of life in four European countries: a population-based study via epidemiological surveillance networks $<7$ Journal of Epidemiology \& Community Health: 2016, 70(5), 430-436

Figure 1 Percentage of patients hospitalised at each of the 90 days before death (non-sudden deaths) Belgium: $\mathrm{N}=1596$; the Netherlands: $\mathrm{N}=633$; Italy: $\mathrm{N}=1827$; Spain: $\mathrm{N}=735$; missing data (care trajectory incomplete): $\mathrm{n}=208(4 \%)$

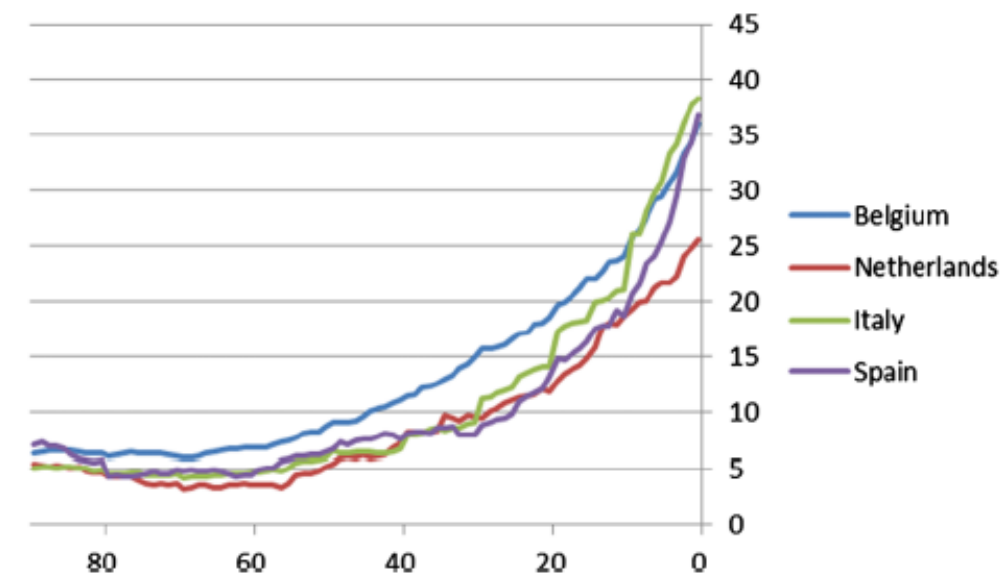

Table 3 Hospital admissions in the last 3 months of life of people who died in hospital non-suddenly

\begin{tabular}{|c|c|c|c|c|c|c|c|c|c|}
\hline \multirow[b]{2}{*}{ Hospital use of patients who died in hospital ${ }^{*}$} & \multicolumn{2}{|c|}{$\begin{array}{l}\mathrm{BE} \\
\mathrm{N}=580\end{array}$} & \multicolumn{2}{|c|}{$\begin{array}{l}\mathrm{NL} \\
\mathrm{N}=177\end{array}$} & \multicolumn{2}{|c|}{$\begin{array}{l}\text { IT } \\
\mathrm{N}=716\end{array}$} & \multicolumn{2}{|c|}{$\begin{array}{l}E S \\
N=274\end{array}$} & \multirow[b]{2}{*}{$\mathrm{p}$-value } \\
\hline & $\mathrm{n}$ & $\begin{array}{l}\text { Per cent } \\
(95 \% \mathrm{CI})\end{array}$ & $\mathbf{n}$ & $\begin{array}{l}\text { Per cent } \\
(95 \% \mathrm{Cl})\end{array}$ & n & $\begin{array}{l}\text { Per cent } \\
(95 \% \mathrm{Cl})\end{array}$ & $\mathrm{n}$ & $\begin{array}{l}\text { Per cent } \\
(95 \% \mathrm{Cl})\end{array}$ & \\
\hline \multicolumn{10}{|l|}{ Time of final hospitalisation } \\
\hline $1-3$ days before death & 104 & $18(15-21)$ & 34 & $20(14-26)$ & 118 & $17(14-20)$ & 65 & $24(19-29)$ & \multirow{4}{*}{$<0.001$} \\
\hline 4-7 days before death & 97 & $17(14-20)$ & 35 & $20(14-26)$ & 134 & $19(16-22)$ & 60 & $22(17-27)$ & \\
\hline 2nd-4th week before death & 277 & $48(44-52)$ & 80 & $46(39-53)$ & 388 & $56(52-60)$ & 122 & $45(39-51)$ & \\
\hline 2 nd-3rd month before death & 96 & $17(14-20)$ & 24 & $14(9-19)$ & 58 & $8(6-10)$ & 23 & $9(6-12)$ & \\
\hline \multicolumn{10}{|l|}{ Location prior to final hospitalisation } \\
\hline Home & 447 & $77(74-80)$ & 148 & $84(79-89)$ & 660 & $92(90-94)$ & 222 & $81(76-86)$ & $<0.001 \dagger$ \\
\hline Nursing/care home & 103 & $18(15-21)$ & 25 & $14(9-19)$ & 32 & $5(3-7)$ & 17 & $6(3-9)$ & $<0.001 \dagger$ \\
\hline Palliative care unithospice & 3 & $0.5(0.0)$ & 0 & $0.0(0.0)$ & 3 & $0.4(0.0)$ & 2 & $0.7(0.0)$ & $\neq$ \\
\hline
\end{tabular}


Pivodic, L., Pardon, K., Miccinesi, G., Vega Alonso, T., Moreels, S., Donker, G., Arrieta, E., Onwuteaka-Philipsen, B., Deliens, L., Block, L. van den. Hospitalisations at the end of life in four European countries: a population-based study via epidemiological surveillance networks $<7$ Journal of Epidemiology \& Community Health: 2016, 70(5), 430-436

Table 4 Factors associated with being admitted to hospital in the course of the last 7 days of life (non-sudden deaths): multivariable logistic regression analysis*

\begin{tabular}{|c|c|c|c|c|c|c|c|c|}
\hline & \multicolumn{8}{|l|}{ OR $(95 \% \mathrm{Cl}) \mathrm{t}$} \\
\hline & \multicolumn{2}{|l|}{ Belgium $\mathrm{N}=1449$} & \multicolumn{2}{|c|}{ The Netherlands $\mathrm{N}=556$} & \multicolumn{2}{|l|}{ Italy $\mathrm{N}=1618$} & \multicolumn{2}{|l|}{ Spain $\mathrm{N}=559$} \\
\hline & OR $(95 \% \mathrm{Cl})$ & $\mathrm{n}(\%)$ & OR $(95 \% \mathrm{Cl})$ & $\mathrm{n}(\%)$ & OR $(95 \% \mathrm{Cl})$ & $\mathrm{n}(\%)$ & OR $(95 \% \mathrm{Cl})$ & $\mathrm{n}(\%)$ \\
\hline \multicolumn{9}{|l|}{ Age (years) } \\
\hline $18-64$ & Ref & $27(14)$ & Ref & $9(9)$ & Ref & $31(16)$ & Ref & $11(20)$ \\
\hline $65-84$ & 1.00 (0.61 to 1.62$)$ & $97(14)$ & $1.43(0.63$ to 3.23$)$ & $35(13)$ & $0.87(0.56$ to 1.37$)$ & $116(15)$ & $1.03(0.47$ to 2.24$)$ & $50(20)$ \\
\hline 85 or over & 1.19 (0.69 to 2.05$)$ & $69(12)$ & $1.15(0.45$ to 2.96$)$ & 19 (11) & $0.64(0.39$ to 1.05$)$ & $83(13)$ & $0.99(0.42$ to 2.34$)$ & $41(16)$ \\
\hline \multicolumn{9}{|l|}{ Gender } \\
\hline Male & Ref & $108(17)$ & Ref & $27(10)$ & Ref & $113(15)$ & Ref & $65(21)$ \\
\hline Female & $0.71(0.51$ to 0.99$)$ & $85(11)$ & $1.48(0.84$ to 2.62$)$ & $36(12)$ & $0.92(0.69$ to 1.22$)$ & $117(14)$ & $0.70(0.43$ to 1.12$)$ & $37(15)$ \\
\hline \multicolumn{9}{|l|}{ Cause of death } \\
\hline Non-cancer & Ref & $123(14)$ & Ref & $39(16)$ & Ref & $133(15)$ & Ref & $63(18)$ \\
\hline Cancer & 1.24 (0.85 to 1.79$)$ & $70(13)$ & 0.61 (0.32 to 1.14$)$ & $24(8)$ & $0.71(0.51$ to 1.00$)$ & $97(13)$ & 0.88 (0.52 to 1.48$)$ & $39(18)$ \\
\hline \multicolumn{9}{|l|}{ Contact with GP } \\
\hline Less than 6 times & Ref & $168(17)$ & Ref & $43(18)$ & Ref & $127(16)$ & Ref & $74(21)$ \\
\hline 6 times or more & $0.41(0.26$ to 0.66$)$ & $25(6)$ & $0.56(0.29$ to 1.10$)$ & $20(6)$ & $0.81(0.60$ to 1.08$)$ & $103(13)$ & $0.82(0.50$ to 1.36$)$ & $28(14)$ \\
\hline \multicolumn{9}{|c|}{ Multidisciplinary palliative care involvement } \\
\hline No & Ref & $144(19)$ & Ref & $56(14)$ & Ref & $145(15)$ & Ref & $64(19)$ \\
\hline Yes & $0.39(0.27$ to 0.56$)$ & $49(7)$ & $0.35(0.15$ to 0.82$)$ & $7(4)$ & $0.98(0.71$ to 1.35$)$ & $85(14)$ & $0.81(0.50$ to 1.32$)$ & $38(17)$ \\
\hline \multicolumn{9}{|c|}{ GP informed of patients' preferred place of death } \\
\hline No & Ref & $144(17)$ & Ref & $40(20)$ & Ref & $164(15)$ & Ref & $89(24)$ \\
\hline Yes & $0.52(0.36$ to 0.74$)$ & $49(8)$ & $0.48(0.25$ to 0.91$)$ & $23(7)$ & $0.98(0.72$ to 1.35$)$ & $66(14)$ & 0.24 (0.13 to 0.44$)$ & $13(7)$ \\
\hline \multicolumn{9}{|c|}{ Longest place of residence in the last year of life } \\
\hline Nursing home/Care home & Ref & $41(8)$ & Ref & $8(7)$ & Ref & $7(7)$ & Ref & $4(6)$ \\
\hline At home/with family & 1.94 (1.28 to 2.94$)$ & $152(16)$ & 2.61 (1.10 to 6.18$)$ & $55(13)$ & 2.17 (0.98 to 4.79$)$ & $223(15)$ & $4.72(1.64$ to 13.57$)$ & $98(20)$ \\
\hline
\end{tabular}

